15

\title{
Влияние способа получения на аморфно-кристаллический переход в сплаве $\mathrm{Fe}_{84} \mathrm{~B}_{16}$
}

\author{
() Д.Ю. Ковалев, ${ }^{1}$ Н.Ф. Шкодич, ${ }^{1}$ С.Г. Вадченко, ${ }^{1}$ А.С. Рогачев, ${ }^{1}$ А.С. Аронин ${ }^{2}$ \\ ${ }^{1}$ Институт структурной макрокинетики и проблем материаловедения им. А.Г. Мержанова РАН, \\ 142432 Черноголовка, Московская обл., Россия \\ ${ }^{2}$ Институт фризики твердого тела РАН, \\ 142432 Черноголовка, Московская обл., Россия \\ e-mail: kovalev@ism.ac.ru
}

Поступило в Редакцию 1 сентября 2018 г.

В окончательной редакции 1 сентября 2018 г.

Принято к публикации 29 июня 2019 г.

\begin{abstract}
Проведены исследования аморфно-кристаллического перехода в сплавах состава $\mathrm{Fe}_{84} \mathrm{~B}_{16}$, полученных спиннингованием расплава и высокоэнергетической механической обработкой. Методом времяразрешающей рентгеновской дифракции показано, что кинетика перехода в кристаллическое состояние определяется способом получения метастабильного состояния сплава. В аморфном сплаве $\mathrm{Fe}_{84} \mathrm{~B}_{16}$, полученном спиннингованием расплава, процесс кристаллизации протекает в течение короткого промежутка времени, не превышающего $1 \mathrm{~s}$, и сопровождается образованием эвтектики $\alpha$-Fe-Fe 3 , c последующим переходом при температуре более $600^{\circ} \mathrm{C}$ метастабильной фазы $\mathrm{Fe}_{3} \mathrm{~B}$ в $\mathrm{Fe}_{2} \mathrm{~B}$ и $\alpha$-Fe. В сплаве, полученном высокоэнергетической механической обработкой, структурные изменения протекают в течение $4-8 \mathrm{~s}$ и переход в состояние с совершенной кристаллической структурой связан с ростом наноразмерных кристаллитов, образовавшихся при обработке материала.
\end{abstract}

Ключевые слова: сплав $\mathrm{Fe}_{84} \mathrm{~B}_{16}$, спиннингование, высокоэнергетическая механическая обработка, аморфнокристаллический переход.

DOI: $10.21883 / J T F .2019 .12 .48490 .327-18$

\section{Введение}

Аморфные сплавы (АC) на основе железа обладают высокой магнитной проницаемостью, индукцией насыщения и малой коэрцитивной силой и применяются для изготовления магнитных экранов, магнитных фильтров и сепараторов, датчиков и т.д. [1]. Основным способом их получения является высокоскоростное охлаждение расплава на вращающемся барабане или диске (спиннингование), что требует высокотехнологичного оборудования. АС также можно получить методом высокоэнергетической механической обработки (ВЭМО) [2-5]. Для получения материалов с необходимыми магнитными свойствами проводят частичную кристаллизацию AC, при этом должны быть выдержаны оптимальные режимы отжига [6]. Протекающая при нагреве аморфных сплавов кристаллизация приводит к изменению их физико-механических свойств, и для них существует проблема термической стабильности. Кристаллизацию лент из аморфного сплава $\mathrm{Fe}_{84} \mathrm{~B}_{16}$, полученных методом спиннингования, исследовали в ряде работ [7-10]. Было показано, что переход из аморфного в кристаллическое состояние при медленном нагреве происходит в две стадии. На первой стадии выделяется фаза $\alpha$-Fe, затем метастабильная фаза $\mathrm{Fe}_{3} \mathrm{~B}$, которая с повышением температуры разлагается на $\alpha$-Fe и $\mathrm{Fe}_{2} \mathrm{~B}$. Исследование аморфных лент [11] показало, что процесс кристаллизации может быть инициирован нагретой спиралью после предвари- тельного подогрева ленты до температуры $T_{0}=300^{\circ} \mathrm{C}$ и протекать в волновом режиме. В то же время исследование близких по составу аморфных лент $\left(\mathrm{Fe}_{80} \mathrm{~B}_{20}\right)$ показало, что при их нагреве со скоростью $20 \mathrm{~K} / \mathrm{min}$ до $420^{\circ} \mathrm{C}$ или при изотермическом отжиге при температуре $380^{\circ} \mathrm{C}$ в течение $1 \mathrm{~h}$ не приводит к кристаллизации [12]. Исследования процессов, протекающих при нагреве лент, полученных прокаткой порошков аморфных сплавов, не проводилось. Цель настоящей работы - исследование методом времяразрешающей динамической рентгенографии перехода аморфного сплава $\mathrm{Fe}_{84} \mathrm{~B}_{16}$, полученного ВЭМО, в кристаллическое состояние и сопоставление с кристаллизацией аморфных лент, полученных спиннингованием расплава.

\section{Материалы и методика эксперимента}

В качестве исходных компонентов для получения сплава $\mathrm{Fe}_{84} \mathrm{~B}_{16}$ ВЭМО использовались порошки железа марки ОСЧ 6-2 (ТУ 6-09-3000-78) и аморфного бора марки марка Б-99В (ТУ 1-92-154-90). Порошки смешивались в фарфоровой ступке в течение 5-10 min в соотношении 84 at.\% Fe и 16 at.\% В. Взвешивание компонентов проводилось с помощью электронных лабораторных весов BM2202M-II с точностью не ниже $0.01 \mathrm{~g}$.

ВЭМО порошковых смесей $84 \mathrm{Fe}-16 \mathrm{~B}$ проводилась в лабораторной шаровой планетарной мельнице

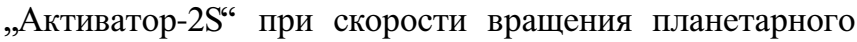


диска $700 \mathrm{rpm}$, скорости вращения барабанов $1400 \mathrm{rpm}$. Предварительно смешанная шихта $84 \mathrm{Fe}-16 \mathrm{~B}$ загружалась в барабаны активатора вместе с измельчающими стальными шарами диаметром 7-8 mm в весовом соотношении $20: 1$ (360 g шаров на $18 \mathrm{~g}$ смеси). Барабаны мельницы герметично закрывались крышками с клапанами для откачки и напуска газа. Сначала производилось вакуумирование до остаточного давления $0.01 \mathrm{~Pa}$, затем барабаны заполнялись аргоном до $4 \mathrm{~atm}$. Смесь порошков $84 \mathrm{Fe}-16 \mathrm{~B}$ подвергалась высокоэнергетическому шаровому размолу продолжительностью до $120 \mathrm{~min}$. Полученные порошки прокатывали в ленты толщиной $250-300 \mu \mathrm{m}$ и шириной $12 \mathrm{~mm}$.

Последовательность структурных и фазовых превращений изучалась методом времяразрешающей рентгеновской дифракции (TRXRD), позволяющим in situ регистрировать изменение структурного и фазового состояний материала при его нагреве [13]. Идея метода состоит в получении последовательности дифракционных спектров с минимальной временной экспозицией в процессе нагрева материала. Исследования проводились на монохроматизированном медном излучении $(\lambda=0.154187 \mathrm{~nm})$ в геометрии Брегга-Брентано на отражение. В случае аморфного сплава $84 \mathrm{Fe} 16 \mathrm{~B}$, полученного спиннингованием расплава, использовалась фольга толщиной $30 \mu \mathrm{m}$ [14]. Исследование сплава, полученного ВЭМО, проводилось на ленте толщиной $200 \mu \mathrm{m}$, полученной прокаткой порошковой смеси $84 \mathrm{Fe}-16 \mathrm{~B}$. Отрезок фольги или ленты размером $15 \times 10 \mathrm{~mm}$ помещался в герметичную камеру с бериллиевыми окнами, оснащенную печью сопротивления. Монохроматизированный пучок направлялся на поверхность образца в его центральной части под углом $20^{\circ}$ и освещал площадку размером $2 \times 10 \mathrm{~mm}$. Регистрация дифракционной картины велась непрерывно в течение нагрева. Экспозиция единичной рентгенограммы составляла $1 \mathrm{~s}$ при нагреве фольги и $2 \mathrm{~s}$ при нагреве ленты. Получали несколько серий по 64 рентгенограммы в каждой серии, характеризующих эволюцию материала в течение нагрева и охлаждения образца. Измерение температуры осуществлялось термопарой $\mathrm{BP} 5 / 20$, диаметром $100 \mu \mathrm{m}$, спай которой находился в контакте с поверхностью образца. Скорость нагрева образцов составляла $250-280 \mathrm{deg} / \mathrm{min}$. Эксперименты проводились в среде гелия при избыточном давлении $1 \mathrm{~atm}$.

Рентгенофазовый анализ материала (РФА) до и после кристаллизации проводился на дифрактометре ДРОН-3М. Регистрация рентгенограмм велась в режиме пошагового сканирования на излучении $\mathrm{Fe} K_{\alpha}$ в интервале углов $2 \theta=30^{\circ}-100^{\circ}$ с шагом $0.02^{\circ}$ и экспозицией $2 \mathrm{~s}$. Определение параметров ячейки проводилось методом внутреннего стандарта с использованием эталона Si (SRM 640D). Оценка параметров тонкой структуры проводилась методом вторых моментов в программном комплексе „Size \& Strain“ НПП „Буревестник“, в качестве внешнего эталона использовался $\mathrm{LaB}_{6}$ (SRM 660A).
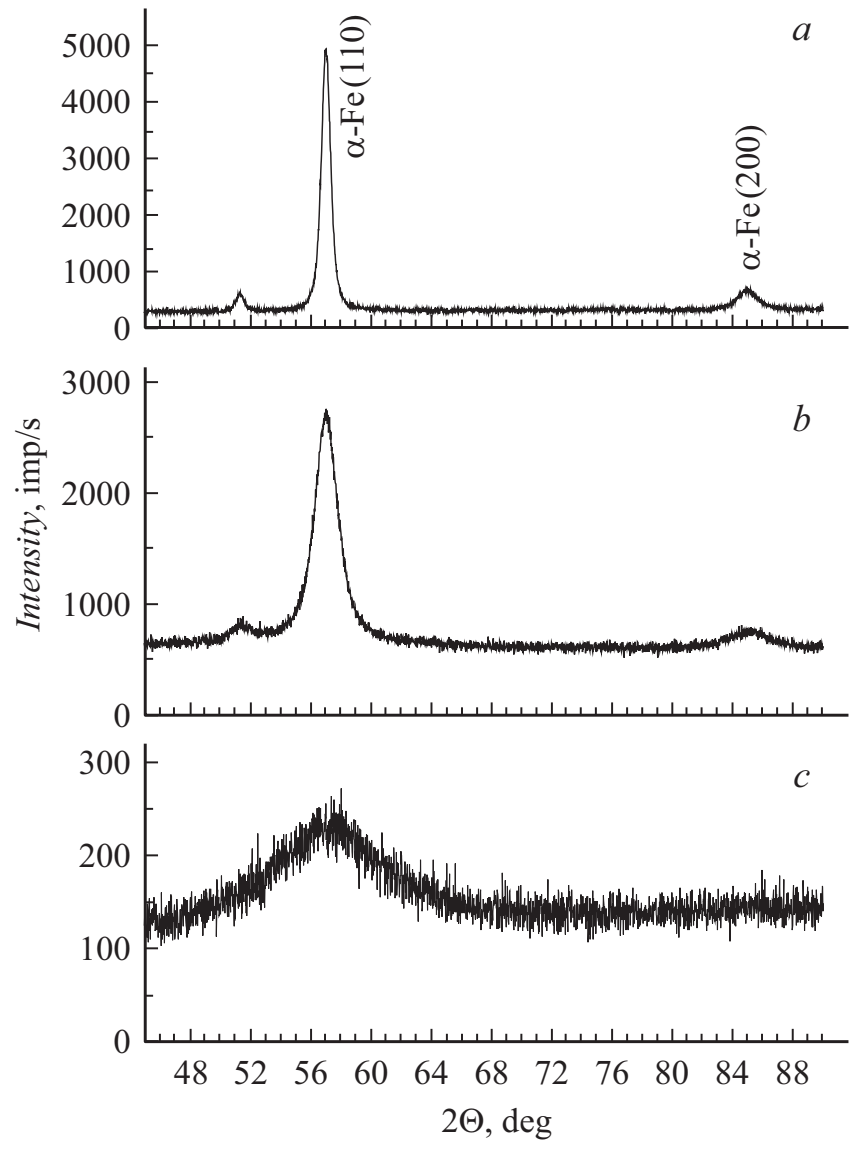

Рис. 1. Рентгенограммы исходных материалов: $a$ - после механической обработки порошка $\mathrm{Fe}, b-$ после механической обработки смеси $84 \mathrm{Fe}-16 \mathrm{~B}, c-$ после аморфного сплава $84 \mathrm{Fe}-16 \mathrm{~B}$, полученного спиннингованием.

\section{Результаты эксперимента и их обсуждение}

РФА порошковой смеси $84 \mathrm{Fe}-16 \mathrm{~B}$ после механической обработки показал, что структурное состояние полученного материала не является рентгеноаморфным (рис. $1, b)$. На рентгенограмме присутствуют сильно уширенные линии фазы $\alpha$-Fе с объемо-центрированной кубической ячейкой (PDF card № 06-0696), характерные для данного углового интервала - (110) и (200) для $\mathrm{K}_{\alpha}$-серии и (110) для $\mathrm{K}_{\beta}$-серии. Размер областей когерентного рассеяния $\alpha$-Fe составил $9 \mathrm{~nm}$. Микроструктура порошковой смеси после механической обработки свидетельствует об образовании композитных частиц дисперсностью $2-10 \mu \mathrm{m}$ (рис. 2). Параметр ячейки фазы на основе $\alpha$-Fe $a=2.8683 \AA$, что выше известного значения параметра ячейки $\mathrm{Fe}$ в порошковой базе данных ICDD (см. таблицу).

[В Для выяснения причины изменения метрики ячейки $\alpha$-Fe был проведен шаровой размол чистого порошка $\alpha$-Fe при аналогичных режимах механической обработки. В этом случае уширение дифракционных линий $\alpha$ - $\mathrm{Fe}$ 
$a$

$b$
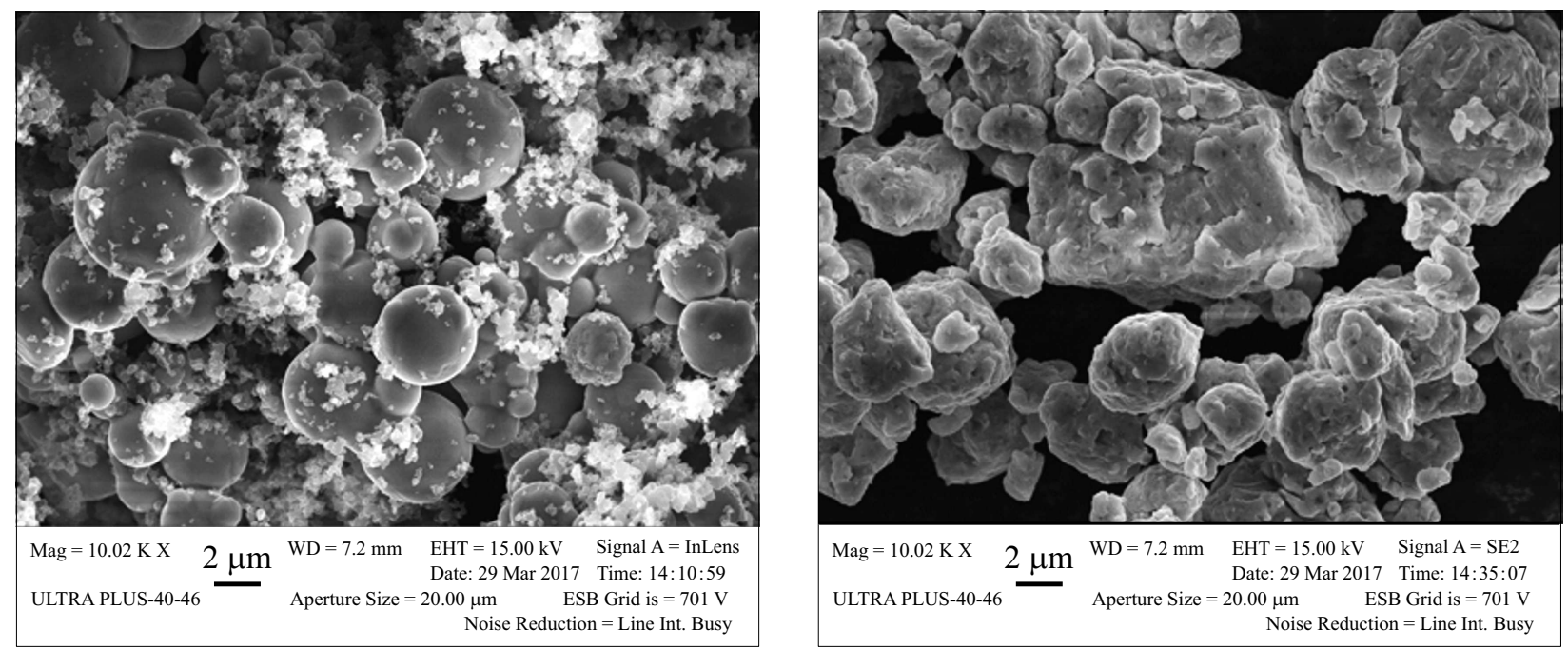

Рис. 2. Микроструктура порошковой смеси $84 \mathrm{Fe}-16 \mathrm{~B}: a-$ до механической обработки, $b-$ после механической обработки в течение $80 \mathrm{~min}$.

Параметры ячейки $\alpha$-Fe в зависимости от метода получения сплава

\begin{tabular}{l|c|c}
\hline Образец & $\begin{array}{c}\text { Параметр } \\
\text { ячейки } \\
\alpha \text {-Fe, } \AA\end{array}$ & $\begin{array}{c}\text { Кристаллические } \\
\text { фазы }\end{array}$ \\
\hline $\mathrm{Fe}$, после ВЭМО & 2.8664 & $\alpha$-Fe \\
\hline $84 \mathrm{Fe}-16 \mathrm{~B}$ после ВЭМО & 2.8683 & $\alpha$-Fe \\
\hline $\begin{array}{l}\text { 84Fe-16В после ВЭМО } \\
\text { и нагрева до 460 }\end{array}$ & 2.8674 & $\alpha$-Fe \\
\hline $\begin{array}{l}\text { Аморфный сплав } 84 \mathrm{Fe} 16 \mathrm{~B} \\
\text { после нагрева до } 460^{\circ} \mathrm{C}\end{array}$ & 2.8681 & $\alpha$-Fe, $\mathrm{Fe}_{2} \mathrm{~B}$ \\
\hline $\begin{array}{l}\text { Аморфный сплав } 84 \mathrm{Fe} 16 \mathrm{~B} \\
\text { после нагрева до } 8000^{\circ} \mathrm{C}\end{array}$ & 2.8681 & $\alpha$-Fe, $\mathrm{Fe}_{2} \mathrm{~B}$ \\
\hline Fe, РDF саrd № $06-0696$ & 2.8664 & $\alpha$-Fe
\end{tabular}

оказалось существенно меньше (рис. $1, a$ ), а параметр ячейки $a=2.8664 \AA$ соответствует порошковой базе дифракционной данных. Следовательно, высокоэнергетическая обработка не приводит к изменению метрики элементарной ячейки чистого $\alpha$-Fe, а структурные изменения связаны с влиянием второго компонента бора. Согласно равновесной фазовой диаграмме $\mathrm{Fe}-\mathrm{B}$, растворимость бора в $\alpha$-Fe незначительна и при комнатной температуре составляет не более 0.06 at.\% [15]. Известно, что механическая активация приводит к существенному сдвигу концентрационных границ твердых растворов за пределы равновесного состояния [16]. Таким образом, ВЭМО смеси $84 \mathrm{Fe}-16 \mathrm{~B}$ приводит к образованию метастабильного твердого раствора бора в $\alpha$-Fe и соответственно к увеличению параметра ячейки
$\alpha$-Fe (см. таблицу). Наблюдаемое различие уширения дифракционных линий $\alpha$-Fe (рис. $1, a, b$ ) также свидетельствует о влиянии бора на структуру материала. Вопрос о концентрации бора в фазе твердого раствора $\alpha$-Fe [B], образовавшегося в результате обработки смеси $84 \mathrm{Fe}-16 \mathrm{~B}$, требует дальнейших исследований. Полное растворение 16 at.\% бора в $\alpha$-Fe маловероятно. Можно предположить, что полученные композиционные частицы содержат наноразмерные кристаллические области твердого раствора $\alpha$-Fe $[\mathrm{B}]$, разделенные областями аморфного бора.

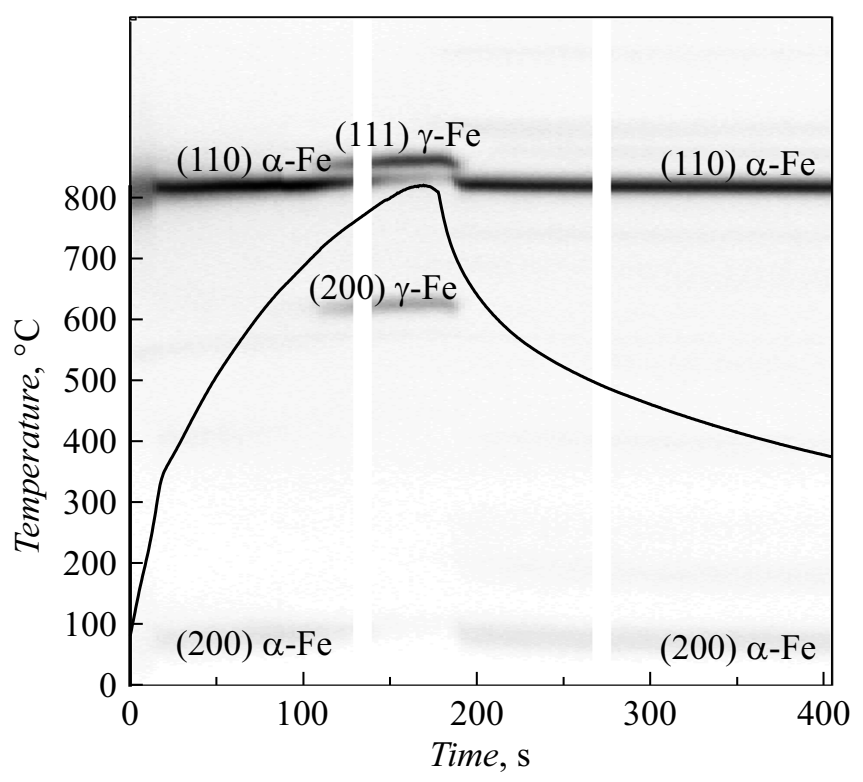

Рис. 3. Дифракционная картина эволюции фазового состава ВЭМО порошка $84 \mathrm{Fe}-16 \mathrm{~B}$ при нагреве. 

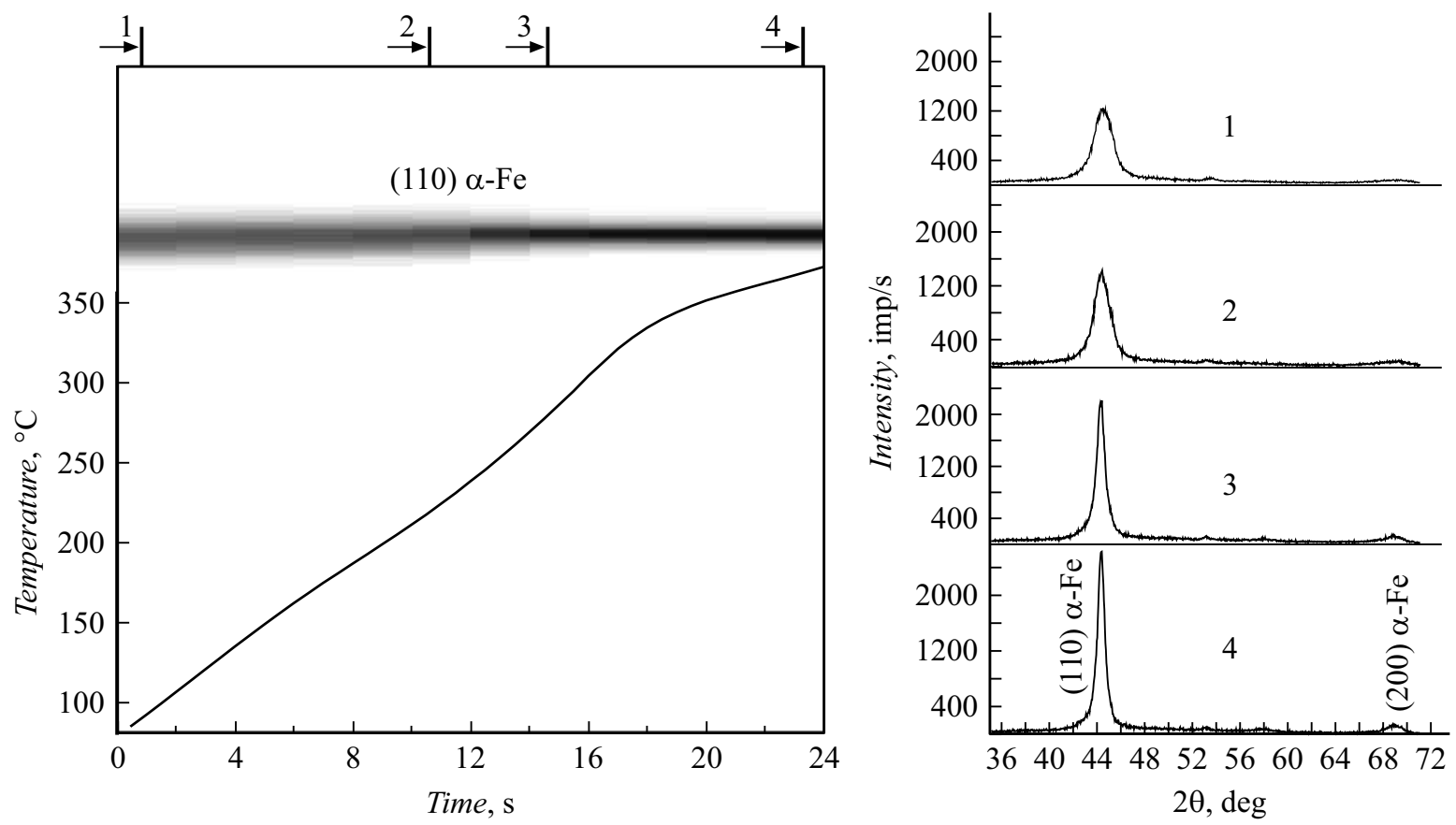

Рис. 4. Начальный участок дифракционной картины при нагреве ВЭМО порошка $84 \mathrm{Fe}-16 \mathrm{~B}$.

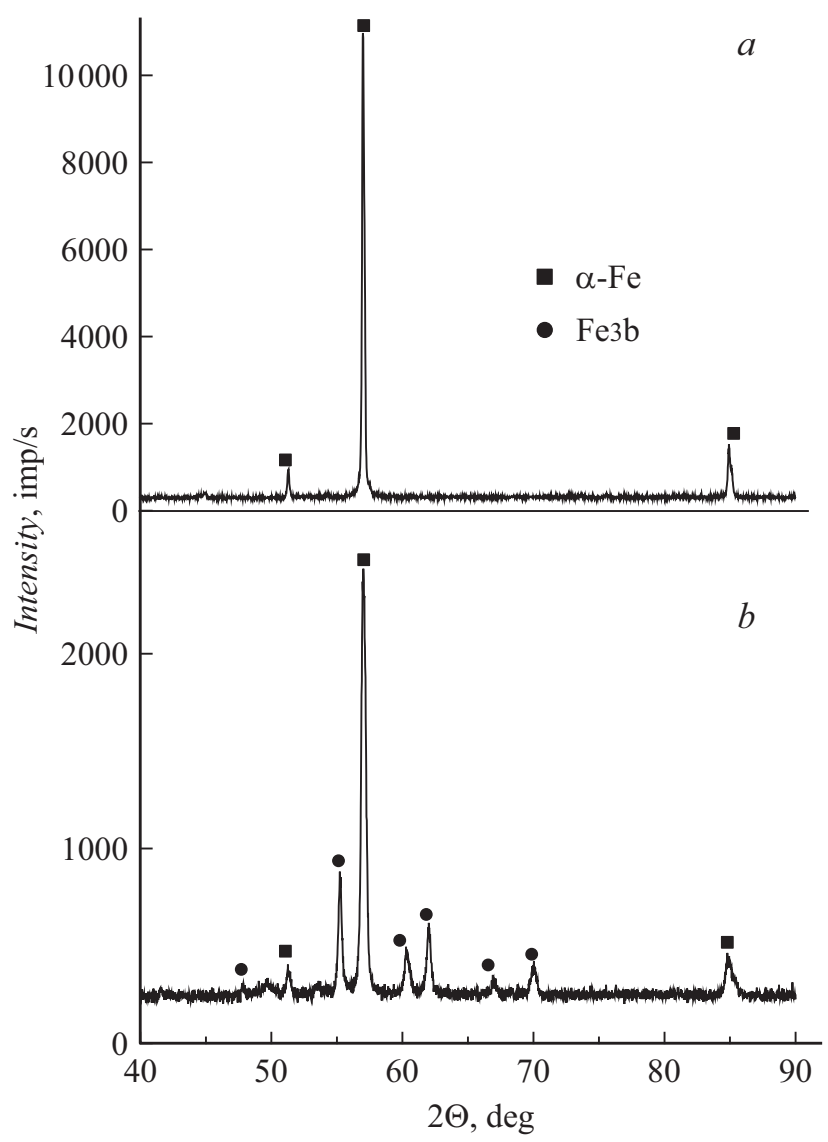

Рис. 5. Рентгенограммы образцов после нагрева: $a-$ ВЭМО смеси $84 \mathrm{Fe}-16 \mathrm{~B}$, максимальная температура нагрева $820^{\circ} \mathrm{C}$, $b$ - аморфного сплава $84 \mathrm{Fe} 16 \mathrm{~B}$, максимальная температура нагрева $460^{\circ} \mathrm{C}$.

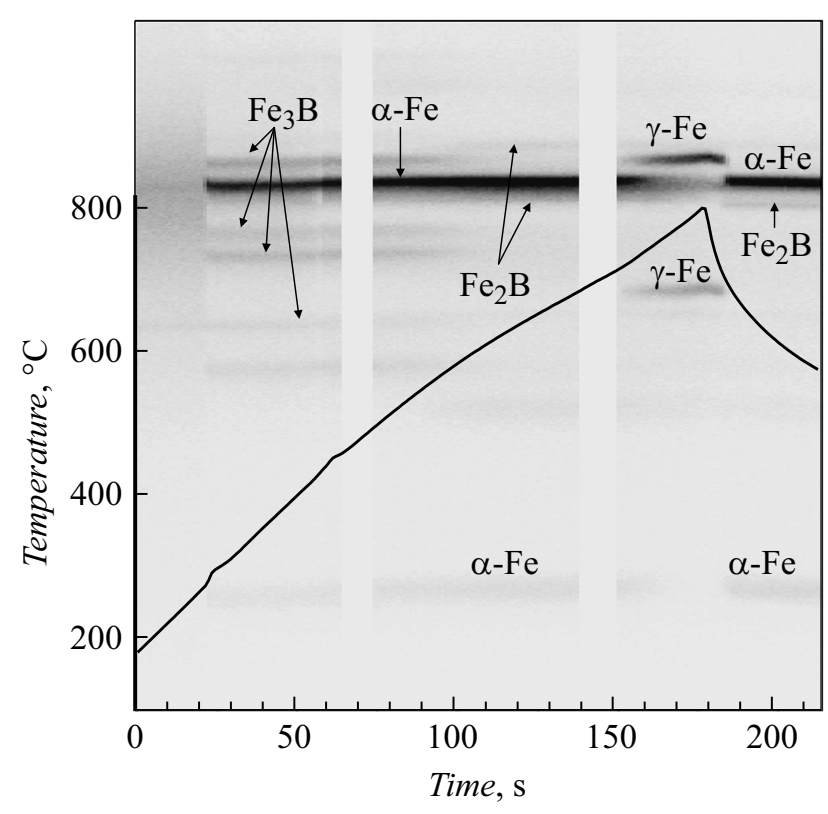

Рис. 6. Дифракционная картина эволюции фазового состава аморфного сплава 84Fe16B при нагреве.

Сплав $\mathrm{Fe}_{84} \mathrm{~B}_{16}$, полученный методом спиннингования расплава, является аморфным. На рентгенограмме присутствует диффузная линия, типичная для аморфных веществ (рис. 1,c). $\mathrm{Fe}_{84} \mathrm{~B}_{16}$ является широко изученным модельным сплавом, кристаллизация которого при медленном нагреве $(\sim 20 \mathrm{deg} / \mathrm{min})$ осуществляется в несколько стадий [7--10,17,18]. Первично происходит выделение равновесной объемно центрированной фазы 

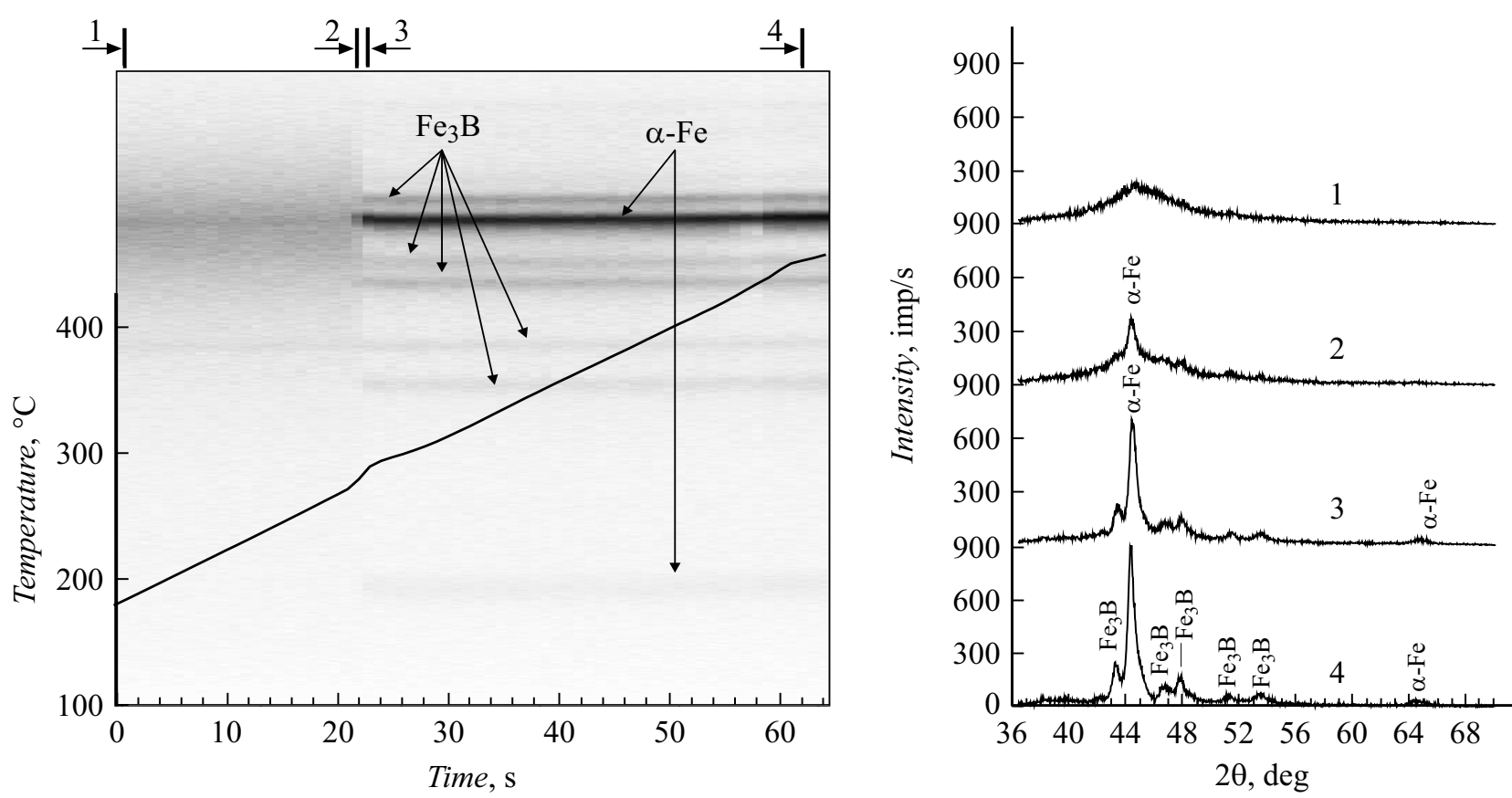

Рис. 7. Начальный участок дифракционной картины при нагреве аморфного сплава 84Fe16B.

$\alpha$ - $\mathrm{Fe}$, а затем метастабильной тетрагональной фазы $\mathrm{Fe}_{3} \mathrm{~B}$. При более высоких температурах фаза $\mathrm{Fe}_{3} \mathrm{~B}$ разлагается на стабильные кристаллические фазы $\alpha$ - $\mathrm{Fe}$ и $\mathrm{Fe}_{2} \mathrm{~B}$. Дифракционная картина, полученная при нагреве ВЭМО порошка $84 \mathrm{Fe}-16 \mathrm{~B}$, представлена на рис. 3. Последовательность из 192 рентгенограмм с экспозицией единичной рентгенограммы $2 \mathrm{~s}$ отображена в виде двумерного поля в координатах угол - время, а интенсивность линии пропорциональна степени черноты поля. На общее дифракционное поле наложена синхронно записанная термограмма нагрева.

Анализ дифракционной картины показывает, что единственной кристаллической фазой, формирующейся при нагреве смеси $84 \mathrm{Fe}-16 \mathrm{~B}$, является фаза $\alpha$-Fe. Увеличение интенсивности и сужение уширенных вследствие ВЭМО линий фазы $\alpha$-Fe начинается при температуре $250-300^{\circ} \mathrm{C}$ и протекает в течение $4-6 \mathrm{~s}$ (рис. 4). Увеличение степени кристалличности $\alpha$-Fe сопровождается появлением слабовыраженного экзотермического пика на термограмме. Наличие теплового эффекта связано с выделением энергии при переходе структуры в равновесное состояние. При дальнейшем нагреве, начиная с температуры $\sim 700^{\circ} \mathrm{C}$, наблюдается фазовый переход $\alpha$-Fe $\rightarrow \gamma$-Fe (рис. 3). При $820^{\circ} \mathrm{C}$ на дифракционном поле присутствуют линии только гранецентрированной фазы $\gamma$-Fe. Обратный переход при охлаждении происходит также при температуре $\sim 700^{\circ} \mathrm{C}$. Для сравнения было проведено исследование эволюции структуры чистого порошка $\alpha$-Fе после ВЭМО при нагреве до $850^{\circ} \mathrm{C}$. Оказалось, что фаза $\alpha$-Fе стабильна и не претерпевает структурных превращений в этом температурном интервале. Действительно, полиморфное превращение $\alpha$-Fe $\leftrightarrow \gamma$-Fe протекает при температуре $912^{\circ} \mathrm{C}$. Очевидно, что существенное снижение температуры перехода связано с растворением бора, который является стабилизатором аустенитной фазы. Рентгенофазовый анализ после охлаждения показал, что материал содержит только фазу $\alpha$-Fe (рис. 5,a). Параметр ячейки фазы $\alpha$-Fe после нагрева уменьшился по сравнению с параметром ячейки фазы $\alpha$-Fе после ВЭМО, однако остался выше известных значений базы PDF 2 (см. таблицу). Таким образом, полученные результаты подтверждают образование твердого раствора бора в $\alpha$-Fе при ВЭМО смеси $84 \mathrm{Fe}-16 \mathrm{~B}$. При нагреве происходит снижение концентрации бора в $\alpha$ - $\mathrm{Fe}$, что проявляется в уменьшении метрики ячейки. Формирования кристаллических боридных фаз железа при заданных температурно-временных параметрах эксперимента не наблюдается.

Дифракционная картина, полученная при нагреве аморфного сплава $\mathrm{Fe}_{84} \mathrm{~B}_{16}$, представлена последовательностью из 192 рентгенограмм с экспозицией единичной рентгенограммы $1 \mathrm{~s}$ (рис. 6).

Анализ дифракционной картины эволюции структуры сплава $\mathrm{Fe}_{84} \mathrm{~B}_{16}$, полученного спиннингованием, показывает, что аморфно-кристаллический переход протекает за время менее $1 \mathrm{~s}$. При скорости нагрева сплава $250-280 \mathrm{deg} / \mathrm{min}$ наблюдается одновременная кристаллизация фаз $\alpha$-Fe и $\mathrm{Fe}_{3} \mathrm{~B}$ (рис. 7). На термограмме нагрева в этот момент отмечен тепловой эффект. Сплав $\mathrm{Fe}_{84} \mathrm{~B}_{16}$ имеет эвтектический состав и кристаллизуется по эвтектическому механизму, образуя колонии размером 50-100 nm (рис. 8). Рентгенограмма сплава после нагрева до $460^{\circ} \mathrm{C}$ также показывает наличие двух фаз $\alpha$-Fe и $\mathrm{Fe}_{3} \mathrm{~B}$ (рис. $5, b$ ). 


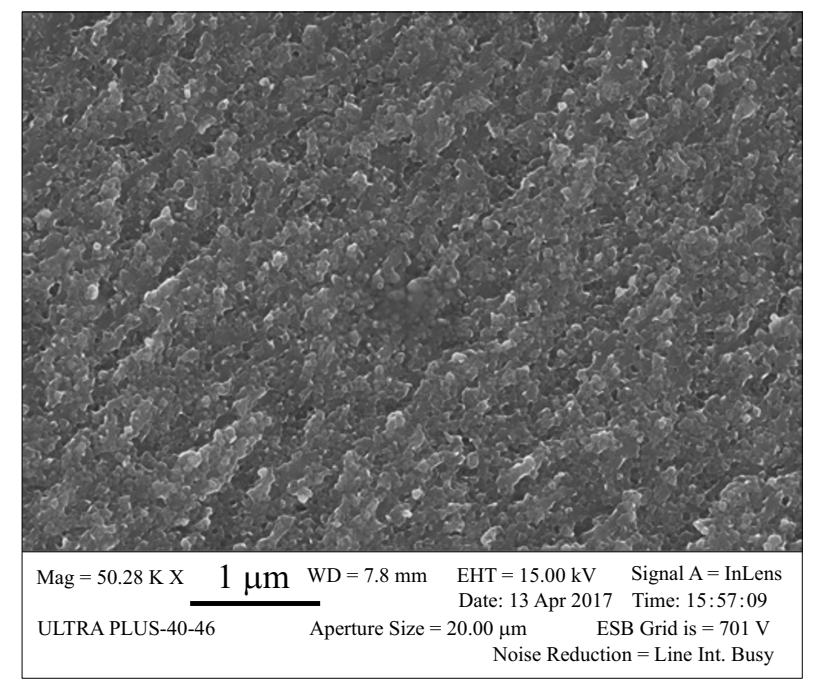

Рис. 8. Микроструктура сплава $84 \mathrm{Fe} 16 \mathrm{~B}$ после нагрева до $460^{\circ} \mathrm{C}$.

Параметр ячейки $\alpha$-Fe в образце, нагретом до $460^{\circ} \mathrm{C}$, составил $2.8683 \AA$, т.е. выше параметра ячейки чистого $\alpha$-Fe $a=2.8664 \AA$ (см. таблицу), что свидетельствует об образовании твердого раствора бора в $\alpha$-Fе. Необходимо отметить близость метрики ячейки $\alpha$ - $\mathrm{Fe}$, полученного в результате ВЭМО $\alpha$-Fe с В, и $\alpha$ - $\mathrm{Fe}$, выделившегося при кристаллизации аморфного сплава $\mathrm{Fe}_{84} \mathrm{~B}_{16}$. Линии метастабильной фазы $\mathrm{Fe}_{3} \mathrm{~B}$ исчезают с дифракционного поля при температуре выше $600^{\circ} \mathrm{C}$. Одновременно наблюдается формирование линий фазы $\mathrm{Fe}_{2} \mathrm{~B}$ (PDF card № 36-1332). При дальнейшем нагреве образца происходит фазовый переход $\alpha$-Fe $\rightarrow \gamma$-Fe (рис. 6). Температура начала полиморфного превращения, как и в случае нагрева ВЭМО порошка, составляла $\sim 700^{\circ} \mathrm{C}$. При охлаждении сплава наблюдается обратный переход $\gamma$-Fe $\rightarrow \alpha$-Fe. Параметр ячейки $\alpha$-Fe после нагрева сплава $\mathrm{Fe}_{84} \mathrm{~B}_{16}$ до $800^{\circ} \mathrm{C}$ снизился по сравнению со сплавом, максимальная температура отжига которого составляла $460^{\circ} \mathrm{C}$, однако сохранился выше параметра ячейки чистого $\alpha$-Fe (см. таблицу).

Сопоставление эволюции структуры и фазового состава аморфного и ВЭМО сплавов $\mathrm{Fe}_{84} \mathrm{~B}_{16}$ при нагреве показывает их существенные различия, связанные со структурными особенностями материала, синтезированного разными методами. Термическое воздействие на аморфный сплав $\mathrm{Fe}_{84} \mathrm{~B}_{16}$ позволяет получить наноразмерную структуру эвтектического типа $\alpha$ - $\mathrm{Fe}-\mathrm{Fe}_{3} \mathrm{~B}$, в то время как нагрев ВЭМО порошковой смеси $84 \mathrm{Fe}-16 \mathrm{~B}$ не приводит к образованию боридных фаз железа, а сопровождается постепенным переходом наноразмерной структуры $\alpha$-Fе в равновесное состояние с совершенной кристаллической структурой. В композитных частицах уже существуют наноразмерные $\sim 9 \mathrm{~nm}$ области феррита, которые являются зародышами для роста кристаллических зерен фазы $\alpha$-Fe. Температура начала процесса, составившая $250-300^{\circ} \mathrm{C}$, близка к температуре
$0.2-0.3 T_{\text {melt }}$, при которой начинаются диффузионноконтролируемые процессы собирательной рекристаллизации в металлах. Процесс является диффузионноконтролируемым и происходит в течение 4-8s. Кристаллизация в случае аморфного сплава $\mathrm{Fe}_{84} \mathrm{~B}_{16}$ носит взрывной характер и связана с одновременным образованием наноразмерных кристаллических областей во всем объеме материала, т.е. с высокой скоростью образования зародышей в аморфной матрице.

\section{Заключение}

Методом времяразрешающей рентгеновской дифракции исследован процесс аморфно-кристаллического перехода в сплавах состава $\mathrm{Fe}_{84} \mathrm{~B}_{16}$, полученных методами спиннингования и высокоэнергетичной механической обработки. Показано, что кинетика перехода в кристаллическое состояние определяется способом получения метастабильного состояния сплава.

В результате ВЭМО порошковой смеси $84 \mathrm{Fe}-16 \mathrm{~B}$ образуются композиционные частицы, содержащие наноразмерные кристаллические области твердого раствора $\alpha$-Fe [B], разделенные областями аморфного бора. Нагрев ВЭМО порошковой смеси $84 \mathrm{Fe}-16 \mathrm{~B}$ не приводит к образованию боридных фаз железа, а сопровождается постепенным переходом наноразмерной структуры $\alpha$-Fe в равновесное состояние с совершенной кристаллической структурой. Переход сплава в кристаллическое состояние протекает диффузионным путем и связан с ростом наноразмерных кристаллитов, образовавшихся при ВЭМО материала и являющихся зародышами для роста кристаллических зерен фазы $\alpha$-Fe.

Нагрев аморфного сплава $\mathrm{Fe}_{84} \mathrm{~B}_{16}$, полученного спиннингованием расплава, приводит к формированию наноразмерной структуры эвтектического типа $\alpha-\mathrm{Fe}-\mathrm{Fe}_{3} \mathrm{~B}$. Кристаллизация аморфного сплава $\mathrm{Fe}_{84} \mathrm{~B}_{16}$ носит взрывной характер и связана с одновременным образованием наноразмерных кристаллических областей во всем объеме материала, т.е. с высокой скоростью образования зародышей в аморфной матрице.

\section{Финансирование работы}

Работа выполнена в рамках государственного задания Института структурной макрокинетики и проблем материаловедения им. А.Г. Мержанова РАН (ИСМАН) тема № 44.1 .

\section{Конфликт интересов}

Авторы заявляют, что у них нет конфликта интересов.

\section{Список литературы}

[1] Zhang Bangwei, Hu Wangyu, Zhu Deqi // Phys. B. 1993. Vol. 183. P. 205.

[2] Politis C. // Int. J. Mod. Phys. B. 2008. Vol. 22. P. 2905. 
[3] Calka A., Radlinski A.P. // Appl. Phys. Lett. 1991. Vol. 58. P. 119.

[4] Shkodich N.F., Vadchenko S.G., Nepapushev A.A., Kovalev D.Yu., Kovalev I.D., Ruvimov S., Rogachev A.S., Mukasyan A.S. // J. Alloys Comp. 2018. Vol. 741. P. 575.

[5] Григорьева Т.Ф., Баринова А.П., Ляхов Н.З. Механохимический синтез в металлических системах. Новосибирск: Параллель, 2008. 311 с.

[6] Kulik T. // J. Non-Cryst. Sol. 2001. Vol. 287. P. 145.

[7] Nakajima T., Kita E., Ino H. // J. Jpn. Institut. Metal. Material. 1987. Vol. 51. P. 263.

[8] Ruckman M.W., Levy R.A., Kessler A., Hasegama R.J. // NonCryst. Sol. 1980. Vol. 40. P. 393.

[9] Новакова А.А., Киселева Т.Ю. // Вестн. Моск. ун-та. Физ. Астрон. 1995. Т. 36. С. 56.

[10] Новакова А.А., Киселева Т.Ю., Александрова И.А. // Вестн. Моск. ун-та. физ. астрон. 1994. Т. 35. С. 102.

[11] Rogachev A.S., Vadchenko S.G., Aronin A.S., Rouvimov S., Nepapushev A.A., Kovalev I.D., Baras F., Politano O., Rogachev S.A., Mukasyan A.S. // Appl. Phys. Lett. 2017. Vol. 111. P. 093105.

[12] Абросимова Г.Е., Аронин А.С., Добаткин С.В., Зверькова И.И., Матвеев Д.В., Рыбченко О.Г., Татьянин Е.В. // ФTT. 2007. T. 49. C. 983.

[13] Kovalev D.Yu., Ponomarev V.I. // Int. J. Self-Propagation Synthesis. 2019. Vol. 28. P. 114-123.

[14] Судзуки К., Фудзимори Х., Хасимото К. Аморфные металлы. М.: Металлургия, 1987. 328 с.

[15] Портной К.И., Левинская М.Х., Ромашов В.М. // Порошковая металлургия. 1969. № 8. С. 66.

[16] Болдырев В.В. В сб.: Фундаментальные основы механической активации, механосинтеза и механохимических технологий / Под ред. Е.Г. Аввакумова. Новосибирск: Издво СО РАH, 2009. С. 15.

[17] Herold U., Koster U. // Z. Metalkunde. 1978. Vol. 69. P. 326.

[18] Abrosimova G.E., Aronin A.S. // Int. J. Rapid Solidif. 1991. Vol. 6. P. 29. 